\title{
Sepsis-related deaths in Brazil: an analysis of the national mortality registry from 2002 to 2010
}

\author{
Leandro U Taniguchi ${ }^{1,2}$, Ana Luiza Bierrenbach ${ }^{1,3}$, Cristiana M Toscano ${ }^{1,4}$, Guilherme PP Schettino ${ }^{1}$ \\ and Luciano CP Azevedo ${ }^{1,2^{*}}$
}

\begin{abstract}
Introduction: Limited population-based epidemiologic information about sepsis' demography, including its mortality and temporal changes is available from developing countries. We investigated the epidemiology of sepsis deaths in Brazil using secondary data from the Brazilian Mortality Information System.

Methods: Retrospective descriptive analysis of Brazilian multiple-cause-of-death data between 2002 and 2010, with sepsis-associated International Classification of Diseases, 10th Revision (ICD-10) code indicated as the cause of death. Population-based sepsis associated mortality rates and trends were estimated. Annual population-based mortality rates were calculated using age-stratified population estimates from the 2010 census provided by the Brazilian Institute of Geography and Statistics as denominators.

Results: The total number of annual deaths recorded in Brazil increased over the decade, from 982,294 deaths reported in 2002 to 1,133,761 deaths reported in 2010. The number of sepsis associated deaths also increased both in absolute numbers and proportions from 95,972 (9.77\% of total deaths) in 2002 to 186,712 deaths (16.46\%) in 2010. The age-adjusted rate of sepsis-associated mortality increased from 69.5 deaths per 100,000 to 97.8 deaths per 100,000 population from 2002 to 2010 ( $P<0.001)$. Sepsis-associated mortality was higher in individuals older than 60 years of age as compared to subjects aged 0 to 20 years (adjusted rate ratio 15.7 (95\% confidence interval (Cl) 15.6 to 15.8$))$ and in male subjects (1.15 (95\% Cl 1.15 to 1.16$)$ ).

Conclusions: Between 2002 and 2010 the contribution of sepsis to all cause mortality as reported in multiple-cause-of-death forms increased significantly in Brazil. Age-adjusted mortality rates by sepsis also increased in the last decade. Our results confirm the importance of sepsis as a significant healthcare issue in Brazil.
\end{abstract}

\section{Introduction}

Sepsis represents a substantial health care and economic burden worldwide. Reported case fatality rates range from 29 to $60 \%$ [1-3]. Treatment costs are estimated at $\$ 16.7$ to $\$ 24.3$ billion annually in the US $[3,4]$. Sepsis incidence has increased in the past decades $[1,5,6]$. In the US, nearly $3 \%$ of patients admitted to hospital have sepsis, and half of these patients are treated in the ICU, accounting for approximately $10 \%$ of all ICU admissions [4]. Similar rates have been described in other developed countries [7-9].

\footnotetext{
* Correspondence: lucianoazevedo@uol.com.br

'Research and Education Institute (IEP), Hospital Sirio-Libanes, Rua Cel, Nicolau dos Santos 69, São Paulo, Brazil

${ }^{2}$ Emergency Medicine Discipline, Hospital das Clínicas da Faculdade de Medicina da Universidade de São Paulo, Av Enéas de Carvalho Aguiar 255

Sala 5023, São Paulo, Brazil

Full list of author information is available at the end of the article
}

In contrast, limited information on sepsis epidemiology, in particular sepsis-related mortality and trends, are available in developing countries. A few recent studies on the topic have been conducted in Brazil [10], China [11], Taiwan [12], Slovak Republic [13], Thailand [14] and Colombia [15]. Nevertheless, reported data are usually not representative, being limited to a single hospital or representing data (for example, from ICU-admitted patients only), which cannot be extrapolated to the population. Up to now, limited population-based estimates of sepsis on a national level for these countries have been conducted and the burden of the disease in those parts of the world remains largely uncharacterized [16]. Likewise, the epidemiology of sepsis-related mortality in Brazil has not been reported from a countrywide perspective.

In this study, we investigated the epidemiology of sepsis deaths in Brazil from 2002 to 2010 using data from the 
Brazilian National Mortality Information System (Sistema de Informações de Mortalidade (SIM)). Our aim was to evaluate trends and provide population-based estimates of sepsis-associated mortality during this period.

\section{Material and methods Study design}

We conducted a descriptive study of a retrospective cohort of multiple-cause-of-death data registered in the National Mortality Registry.

\section{Sources of data}

Data routinely reported to the SIM for the years 2002 to 2010, extracted on 28 March 2012, were considered for the analysis. SIM is an electronic, case-based national mortality registry, which derives its information from death certificates. Sepsis-related deaths from 2002 to 2010 were identified based on International Classification of Disease, 10th Revision (ICD-10) codes reported for each record of the registry. Information about cause of death available on death certificates includes: part 1: the underlying cause-of-death, the immediate cause-of-death, and the sequence of contributing causes from the underlying to the immediate cause; and part 2: any conditions not directly leading to death but contributing to it. Codes recorded as underlying and/or contributing cause-of-death were considered. In Brazil, death certificate information is collected by trained mortality coders (after appropriate training according to the World Health Organization standards). They work in statistical regional offices of the Ministry of Health and use mortality-coding software specifically designed for this purpose. This practice has remained constant since 1996 (when ICD-10 was introduced in Brazil). Population estimates were obtained from the Brazilian Institute of Geography and Statistics (Instituto Brasileiro de Geografia e Estatística (IBGE)) [17].

\section{Case definitions}

Sepsis-associated deaths were defined as those in which the following ICD-10 codes were indicated as any of the causes of death in part 1 of the death certificate: A39, $\mathrm{A} 40$ and A41 (including their associated subcodes), A02.1, A22.7, A26.7, A32.7, A 39.2, A39.4, A42.7, B00.7, B37.7 (Additional file 1: Table S1). In addition, in order to identify cases of deaths potentially related to severe sepsis, we selected cases with ICD-10 codes related to any bacterial, protozoan, viral or fungal infections with one or more codes related to organ dysfunction in part 1 of the death certificate (as such, cases of deaths potentially related to severe sepsis include cases of sepsis-associated deaths). Presence of organ dysfunction (cardiovascular, hematologic, hepatic, metabolic, neurologic, respiratory and renal) considered codes listed as the underlying or any other cause of death from part 1 of the death certificate
(Additional file 1: Table S2). Presence of underlying comorbidities considered codes listed on parts 1 and 2 of the death certificate (Additional file 1: Table S3). These definitions are slightly modified versions of classifications used by other authors in similar studies $[1,4-6,16,18]$.

When two or more codes were reported in a single cause-of-death variable, separated by a space or a symbol, both of them contributed to the analysis. For this reason, when adding the number of the total reported number of organ failures or comorbidities, more than four may have been reported, despite four being the number of lines available in the death certificate to report immediate and contributing causes-of-death.

\section{Exclusion criteria}

Neonatal and puerperal sepsis-associated deaths (ICD-10 codes P36 and O85, respectively) were excluded from this analysis, as their causes, epidemiological features, prevention and control strategies are different to those related to general sepsis.

\section{Data analysis}

From all deaths recorded in the registry during the study period, all cases of sepsis-associated deaths and deaths potentially related to severe sepsis were identified. The proportion of sepsis deaths for the study period and for every 2-year period was calculated considering the number of sepsis-associated deaths in the numerator and the total number of deaths in Brazil in the denominator.

Annual population-based mortality rates were calculated for the study period, considering the number of sepsis-associated deaths and deaths potentially related to severe sepsis as numerators and the total Brazilian population by year in the denominator. We used the direct standardization method to standardize mortality rates in order to compare them over time. Crude and standardized annual mortality rates were calculated for the period of 2002 to 2010, considering the Brazilian 2010 Census agestratified population as the standard. We describe the proportion of sepsis-associated deaths by gender, age group, place of occurrence, presence of comorbidities and presence of organ dysfunction. We also tested the association between the above variables and sepsis-associated deaths for the year of 2010.

We used Poisson regression with a logarithmic link function and an offset equal to the log of the population to explore the effects of age group and gender on sepsisassociated deaths mortality rates. Multivariate analysis was used to control for confounders and test for interactions. $P$-values $<0.05$ were considered statistically significant. However, as the analyses were done with national data and therefore include a large number of events, even small differences can become significant. Thus, when a 
significant interaction was observed, we decided to report the stratified rates only when the interaction term represented $10 \%$ or more of the combined effect of its variables. Analyses were done using Stata 12 (Stata Corporation, College Station, Texas, USA).

Ethical approval for this study was obtained from the Ethical Committee of Hospital Sírio-Libanês, Sao Paulo, Brazil (CAAE: 01063212.1.0000.5461 - 3 January 2012).

\section{Results}

We identified a total of 9,407,764 deaths in Brazil from 2002 to 2010. The annual number of deaths recorded in SIM increased over time. While in 2002, 982,294 deaths were reported, in 2010 this number increased to $1,133,761$ deaths. Similarly, there is an increase in the number of sepsis-associated deaths and deaths potentially related to severe sepsis during the entire period (Figure 1). The proportion of sepsis-associated deaths relative to the total of deaths also increased significantly from $9.77 \%$ in 2002 to $16.46 \%$ in 2010 (Table 1).

ICD-10 code A41.9 for Septicemia unspecified was indicated in $98.75 \%$ of all sepsis-associated deaths. Chapter XVIII codes R65.1 (Systemic inflammatory response syndrome (SIRS)) and R65.2 (Severe sepsis) were not reported in the SIM database during the study period.

Reported characteristics of sepsis-associated deaths by period are shown in Table 2. The vast majority of sepsis deaths occurred in the hospital. More than two thirds of the patients who died with sepsis had one comorbidity or no comorbidities. Of these, cancer, diabetes mellitus and arterial hypertension were the most frequent. Roughly $20 \%$ of the sepsis-associated deaths were in patients with had at least one organ failure, the respiratory system being the most frequent dysfunction.

Crude sepsis-associated mortality rates increased $77.5 \%$ during the study period, from 55.1 in 2002 to $97.8 / 100,000$ population in 2010. After age standardization, mortality rates increased $40.7 \%$ from 69.5 in 2002 to 97.8 deaths per 100,000 population in 2010 . This is equivalent to a linear increase of 3.5 deaths/100,000 population per year $(P<0.001)$ (Figure 2).

When analyzing crude sepsis-associated deaths rates by age group, two peaks were demonstrated, the first corresponding to deaths in early childhood, the second in the elderly (Figure 3 ).

Table 3 shows the crude and adjusted rate ratios of sepsis-associated deaths for age groups and gender, considering all study years. Sepsis-associated mortality increased significantly by age group, being particularly higher in the elderly (60 years and older). Also, sepsisassociated mortality is significantly higher $(15 \%)$ in men when compared to women.

\section{Discussion}

To our knowledge, this is the first longitudinal, populationbased study of deaths associated with sepsis in Brazil. We found that $12.9 \%$ of all Brazilian deaths from 2002 to 2010 were related to sepsis, and that both crude and age-standardized sepsis-associated mortality rates were increasing significantly in this period of time. Two peaks of sepsis-related mortality corresponding to early childhood and in the elderly were observed. Moreover, sepsisassociated mortality rates were higher for men.

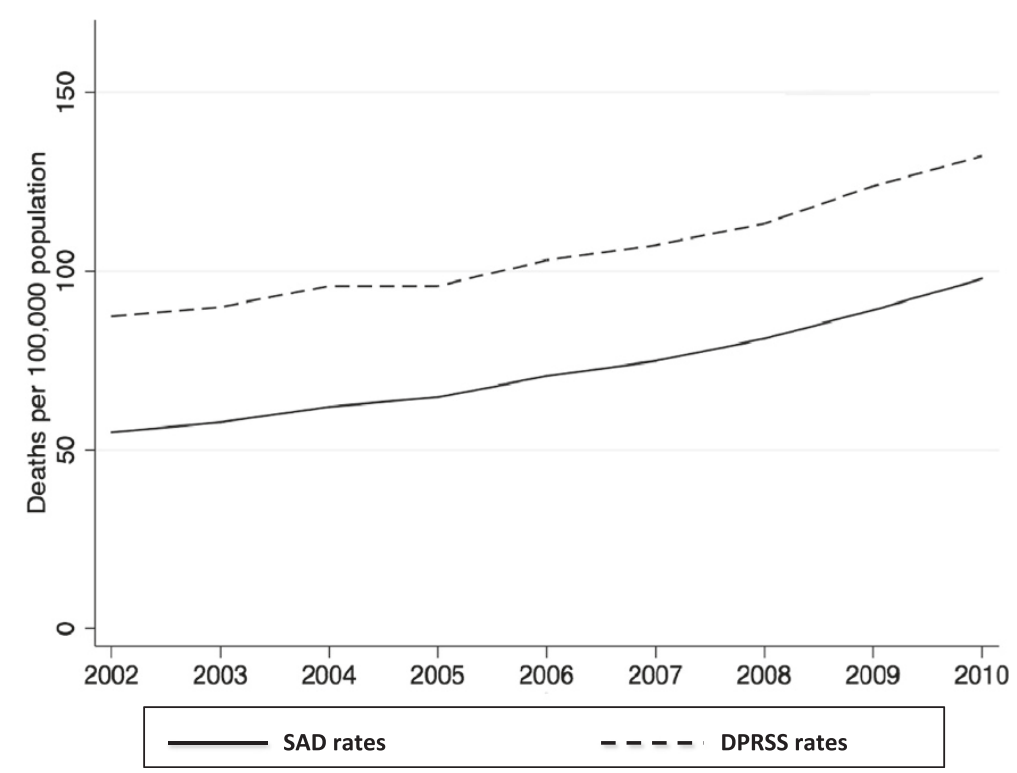

Figure 1 Rates of sepsis-associated deaths (SAD) and deaths potentially related to severe sepsis (DPRSS). Brazil, 2002 to 2010. 
Table 1 Number of total deaths, sepsis-associated deaths, deaths potentially related to severe sepsis, and population during the study period

\begin{tabular}{llllll}
\hline Year & Total deaths & SAD & DPRSS & Population & $\begin{array}{l}\text { \% SAD/total } \\
\text { deaths }\end{array}$ \\
\hline 2002 & 982,294 & 95,972 & 152,482 & $174,632,932$ & 9.77 \\
2003 & $1,002,340$ & 102,065 & 159,181 & $176,876,251$ & 10.18 \\
2004 & $1,024,073$ & 111,202 & 171,751 & $179,108,134$ & 10.85 \\
2005 & $1,006,828$ & 119,184 & 176,643 & $184,184,074$ & 11.83 \\
2006 & $1,031,150$ & 131,951 & 192,475 & $186,770,613$ & 12.79 \\
2007 & $1,047,528$ & 141,709 & 203,138 & $189,335,191$ & 13.52 \\
2008 & $1,077,007$ & 153,748 & 214,964 & $189,612,814$ & 14.27 \\
2009 & $1,102,783$ & 170,668 & 237,032 & $191,481,045$ & 15.47 \\
2010 & $1,133,761$ & 186,712 & 252,263 & $190,755,799$ & 16.46 \\
Trend & NA & 0.004 & 0.004 & NA & 0.003 \\
P-values & & & & & \\
\hline
\end{tabular}

Brazil, 2002 to 2010. SAD, sepsis-associated deaths; DPRSS, deaths potentially related to severe sepsis. NA, not applicable.

Sepsis burden is significant both in developed [1-8] and developing countries [10-15]. Our data demonstrate an increase in sepsis-associated deaths (absolute increase of 6.7\%) in eight years. Other authors have demonstrated a similar increase in the number of sepsis-associated deaths using hospitalization databases in the US $[1,5,6]$. While Melamed et al. demonstrated a crude sepsis mortality rate of $50.49 / 100,000$ population in 1999 to 2005 [5], Lagu et al. reported rates of 87/100,000 in 2007 [3], also using secondary data from hospitalization databases. This represents an increase of $72 \%$ in mortality rates, which may be related to increasing trends in sepsis mortality rates in the US. Similarly, we observed an increase of $77.5 \%$ in an equivalent period of time in Brazil.

Several authors demonstrated that sepsis-associated mortality rates, the incidence of sepsis and the hospitalizations due to sepsis are increasing [1-3,5,6]. However, age-adjusted case-fatality rates have been decreasing over time in several studies conducted in developed countries, possibly reflecting improvement in access to healthcare and better management of sepsis admitted to hospitals [1,3,5]. Recently, studies reported that better compliance with guidelines for sepsis treatment was associated with improved outcomes [19-21]. This might explain why case-fatality is decreasing. Another issue acknowledged by Lagu et al. is the difference in coding of sepsis and organ dysfunction by hospitals when filling hospitalization admission and discharge reports, due to financial issues [3]. As some of these databases are used for reimbursement purposes, this might be linked to financial incentives for coding organ dysfunctions, leading to an increased observed incidence of mild dysfunctions [3]. Our analysis was conducted using data obtained from the
Table 2 Reported characteristics of sepsis-associated deaths

\begin{tabular}{|c|c|}
\hline Characteristics & Values \\
\hline Age, years, mean $\pm S D$ & $64.4 \pm 23.4$ \\
\hline Male sex, \% & 51.1 \\
\hline Died in hospital, \% & 94.8 \\
\hline \multicolumn{2}{|l|}{ Comorbidities, \% } \\
\hline Cancer & 14.6 \\
\hline Diabetes mellitus & 13.3 \\
\hline Arterial hypertension & 11.0 \\
\hline Stroke & 6.3 \\
\hline Renal failure & 5.8 \\
\hline Chronic obstructive pulmonary disease & 5.7 \\
\hline Congestive heart disease & 5.2 \\
\hline Coronary artery disease & 3.4 \\
\hline Hepatic condition & 2.3 \\
\hline HIV infection & 2.5 \\
\hline Alcohol-derived diseases & 2.0 \\
\hline \multicolumn{2}{|l|}{ Number of comorbidities, \% } \\
\hline 0 & 46.3 \\
\hline 1 & 38.4 \\
\hline 2 & 12.6 \\
\hline 3 & 2.5 \\
\hline $4+$ & 0.2 \\
\hline \multicolumn{2}{|l|}{ Organ failure, \% } \\
\hline Respiratory & 13.5 \\
\hline Renal & 4.5 \\
\hline Cardiac & 2.4 \\
\hline Hepatic & 0.9 \\
\hline Neurologic & 0.6 \\
\hline Metabolic & 0.5 \\
\hline Hematological & 0.3 \\
\hline \multicolumn{2}{|l|}{ Number of organ failures, \% } \\
\hline 0 & 79.0 \\
\hline 1 & 19.4 \\
\hline 2 & 1.5 \\
\hline $3+$ & 0.1 \\
\hline
\end{tabular}

Brazil, 2002 to 2010.

national mortality registry, which are generated from death certificates and not used for reimbursement purposes. This data source has fewer fields to input information (in comparison to hospital databases), with no direct relation to clinical data. This might explain why most sepsisassociated deaths had no organ failure reported, which is unlikely, as probably cases of sepsis will have some organ failure at some point over the course of the disease leading to death. This is clearly a restriction of administrative databases and, as such, a limitation of the present study. 


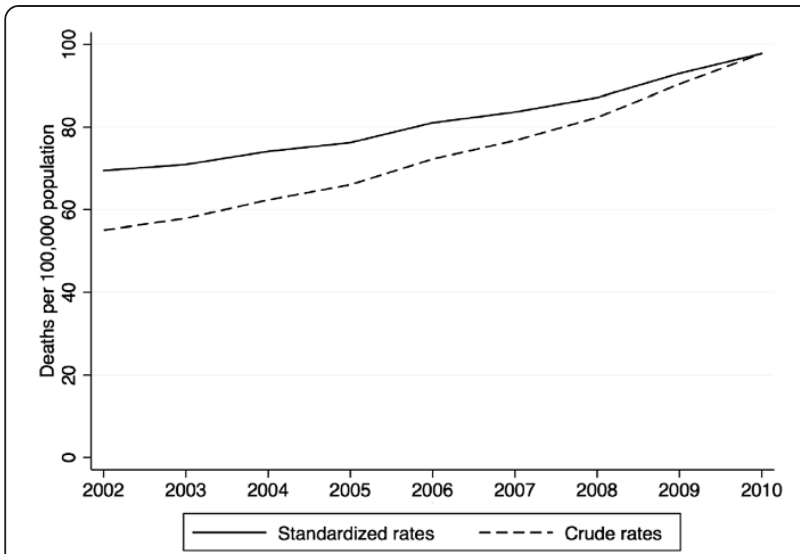

Figure 2 Crude and age-standardized (using the 2010 Census population as the standard) sepsis-associated mortality rates per 100,000 population. Brazil, 2002 to 2010.

Previous studies conducted in Brazil analyzing ICU patients provided relevant information on some epidemiologic aspects of sepsis. The BASES study, which evaluated five Brazilian ICUs in 2001 to 2002, observed 30.5 cases of sepsis/100 ICU admissions. The overall mortality rate for sepsis was $21.8 \%$, and it was $52.2 \%$ for patients with septic shock [10]. In another study, $13.4 \%$ of ICU admissions were due to severe sepsis, with mortality rates as high as $59.4 \%$ [22]. Not only are sepsis ICU admission rates high, but so too are the reported associated costs. Sogayar et al. showed a median ICU cost of U\$9,632 per patient in a Brazilian study conducted in 21 mixed ICUs in private and public hospitals [23]. To date, trends in the nationwide burden of sepsis over time have not been reported in Brazil. All Brazilian sepsis-related studies have only been done in ICU patients, which might underestimate the overall epidemiologic burden of sepsis in the country. Rezende et al. has demonstrated

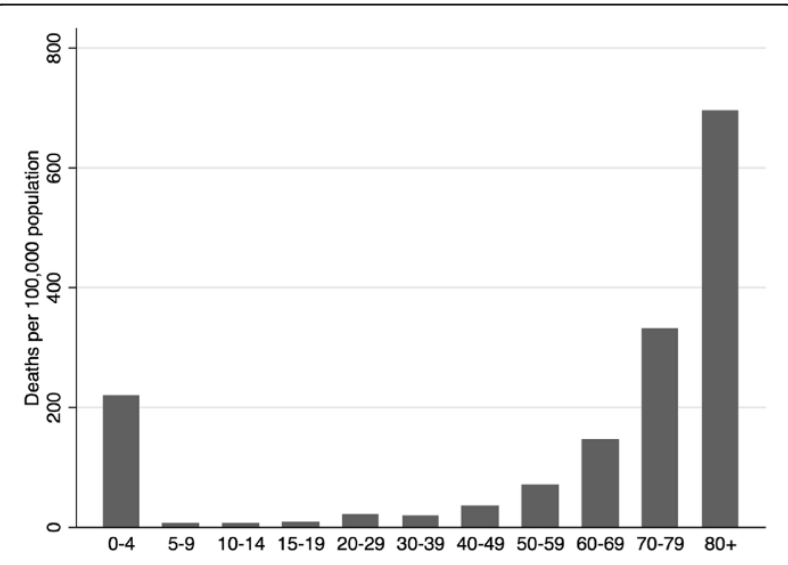

Figure 3 Crude sepsis-associated mortality rates by age-group. Brazil, 2002 to 2010.
Table 3 Sepsis-associated mortality rates and rate ratios, by age-group and gender

\begin{tabular}{|c|c|c|c|}
\hline Characteristic & $\begin{array}{l}\text { Sepsis-associated } \\
\text { mortality rates per } \\
100,000 \text { population }\end{array}$ & $\begin{array}{l}\text { Crude rate } \\
\text { ratios }(95 \% \mathrm{Cl})\end{array}$ & $\begin{array}{l}\text { Adjusted rate } \\
\text { ratios }(95 \% \mathrm{Cl})\end{array}$ \\
\hline \multicolumn{4}{|l|}{ Age groups } \\
\hline 0 to 19 years (ref) & 19.3 & 1.0 & 1.0 \\
\hline 20 to 60 years & 34.2 & $1.77(1.76,1.79)$ & $1.78(1.76,1.79)$ \\
\hline $60+$ years & 297.3 & $15.6(15.5,15.7)$ & $15.7(15.6,15.8)$ \\
\hline \multicolumn{4}{|l|}{ Gender } \\
\hline Female (ref) & 67.8 & 1.0 & 1.0 \\
\hline Male & 78.2 & $1.08(1.07,1.08)$ & $1.15(1.15,1.16)$ \\
\hline
\end{tabular}

Brazil, 2002 to 2010. ref, reference.

that only one third of patients with severe sepsis admitted to the emergency department of a public tertiary urban hospital in Brazil were referred to an ICU [24]. This suggests that the true sepsis prevalence in hospitals may be much higher than the one observed in ICU only. Resource constraints such as scarcity of ICU beds and high ICUrelated costs could be some of the factors that might explain why septic patients are not always admitted to an ICU. The consequence of this fact may be the higher mortality due to sepsis in Brazil, as demonstrated in previous studies [25]. The results obtained in this study, due to its population characteristic, are significant to unequivocally characterize the importance of the disease nationwide.

A recent study evaluated sepsis-associated mortality in England using data from a national mortality database comprising data derived from death certificates [26]. The authors observed that $4.7 \%$ of deaths between 2001 and 2010 were associated with sepsis (compared to $12.9 \%$ in our study in an equivalent period of time). Similarly to our study, mortality rates were higher in men and increased by age group, with the most significant increase in the elderly. There are relevant advantages of using nationwide routinely collected data such as in our study and the English study for assessing the epidemiology of sepsis. First, long time-series data are readily available for analysis. Second, these data are usually representative of the whole population, and therefore provide a better picture of the nationwide situation. The main disadvantage of using such data sources is that nationwide populationbased databases, hospitalization and mortality, are mainly collected for administrative purposes. As such, they tend to have some degree of incompleteness and are more subject to systematic and random errors when compared with data from observational studies. Our data on the low prevalence of organ dysfunction in sepsis-associated deaths from our database is an example of these possible limitations.

In this study, we found an increase in sepsis mortality with age after the first years of life, especially in the elderly subgroup. Others authors have previously demonstrated 
a similar increase in incidence and mortality of sepsis related to age, reinforcing the generalizability of our findings $[4,5,12]$. Since there is now an escalation in the proportion of older patients in our country, and the mortality is higher in this subgroup, a further increment in sepsis-associated mortality rates might be expected in the next few years. It should be acknowledged that this change in life expectation might also increase the population at higher risk of death after a septic episode, which could be one of the reasons for the increment in sepsisassociated deaths observed in our study.

Besides the limitations described previously, another possible explanation for the increase in sepsis deaths over time observed in our study is an improvement in notifications of sepsis in death certificates and in data acquisition. Rhee et al. recently discussed this possibility, emphasizing the lack of reliable tools to measure sepsis incidence. More important, they suggested that hospitalization rates of sepsis in America are increasing, but infection rates are stable or decreasing. This may be due to differences in coding practice associated with changes in reimbursement values instead of a true increase in sepsis rates [27]. However, in Brazil, there are no major modifications in reimbursement values for coding associated with organ dysfunction. In addition, we searched for pneumonia-associated deaths in the same period in our country and we observed an increase at a similar rate to sepsis-associated deaths (data not shown). This is in clear contrast to Rhee's data, and reinforces the burden of infection-associated deaths in Brazil. In fact, it is possible that our results still underestimate the real burden of sepsis, as death certificate analysis might underestimate infections as a cause of death [28]. Finally, another limitation of our study is the data abstraction using ICD-10 coding from death certificates. Other approaches (such as Angus Implementation) are available, but inaccuracies are still present [29,30]. On the other hand, previous studies using death certificates have been published with results similar to ours [6,26], strengthening our findings.

\section{Conclusions}

In conclusion, sepsis-associated mortality in Brazil is relevant due to its increasing number of deaths in recent years, a trend not related solely to the aging population. Our data confirm the importance of sepsis as a significant healthcare issue in Brazil.

\section{Key messages}

- This is the first longitudinal, population-based study of sepsis-associated deaths in Brazil

- From 2002 to 2010, 12.9\% of all Brazilian deaths were related to sepsis and both crude and age-standardized sepsis associated mortality rates are increasing
- In Brazil, sepsis-related deaths are higher in early childhood and the elderly, and males have higher rates of death than females.

\section{Additional file}

Additional file 1: Table S1. International Classification of Diseases 10th Revision (ICD-10) codes used for definition of sepsis-associated deaths. Table S2. International Classification of Diseases 10th Revision (ICD-10) codes used for definition of organ dysfunction. Table S3. International Classification of Diseases 10th Revision (ICD-10) codes used for definition of comorbidity. Table S4. International Classification of Diseases 10th Revision (ICD-10) codes used for definition of infection (bacterial, protozoan, viral or fungal).

\section{Abbreviations}

DPRSS: deaths potentially related to severe sepsis; ICD-10: International Classification of Diseases, 10th Revision; SAD: sepsis-associated deaths; SIM: Sistema de Informações de Mortalidade (Brazilian National Mortality Information System).

\section{Competing interests}

The authors declare that they have no competing interests.

\section{Authors' contributions}

LUT, ALB, CMT and LCPA conceived the study. ALB and CMT collected and analyzed data. LUT, ALB, CMT, GPPS and LCPA participated in interpretation of data. LUT, ALB, CMT, GPPS and LCPA have been involved in drafting the present manuscript. All authors read and approved the final manuscript.

\section{Acknowledgements}

This study was supported by institutional funding from Education and Research Institute, Hospital Sirio-Libanes, São Paulo, Brazil. The institution where the study was carried out was the Research and Education Institute (IEP), Hospital Sírio-Libanês, São Paulo, Brazil. Partial results of this study were presented as an oral communication at Sepsis 2013 International Sepsis Forum, 5 to 6 November, 2013, Rio de Janeiro, Brazil.

\section{Author details}

${ }^{1}$ Research and Education Institute (IEP), Hospital Sirio-Libanes, Rua Cel, Nicolau dos Santos 69, São Paulo, Brazil. ${ }^{2}$ Emergency Medicine Discipline, Hospital das Clínicas da Faculdade de Medicina da Universidade de São Paulo, Av Enéas de Carvalho Aguiar 255 Sala 5023, São Paulo, Brazil. ${ }^{3}$ Sanas Epidemiology and Research, Avenida Paulista 2073, Edifício Horsa 1, salas 703/704, São Paulo, Brazil. ${ }^{4}$ Department of Collective Health, Federal University of Goias, Rua $235 \mathrm{~s} / \mathrm{n}$, Goias, Brazil.

Received: 15 July 2014 Accepted: 20 October 2014

Published online: 05 November 2014

\section{References}

1. Martin GS, Mannino DM, Eaton S, Moss M: The epidemiology of sepsis in the United States from 1979 through 2000. N Engl J Med 2003, 348:1546-1554.

2. Annane $D$, Aegerter $P$, Jars-Guincestre MC, Guidet B, CUB-Réa Network: Current epidemiology of septic shock: The CUB-Rea Network. Am J Respir Crit Care Med 2003, 168:165-172.

3. Lagu T, Rothberg MB, Shieh MS, Pekow PS, Steingrub JS, Lindenauer PK: Hospitalizations, costs, and outcomes of severe sepsis in the United States 2003 to 2007. Crit Care Med 2012, 40:754-761.

4. Angus DC, Lind-Zwirble WT, Lidicker J, Clermont G, Carcillo J, Pinsky MR: Epidemiology of severe sepsis in the United States: Analysis of incidence, outcome, and associated costs of care. Crit Care Med 2001, 29:1303-1310

5. Dombrovskiy WY, Martin AA, Sunderram J, Paz HL: Rapid increase in hospitalization and mortality rates for severe sepsis in the United States: A trend analysis from 1993 to 2003. Crit Care Med 2007, 35:1244-1250. 
6. Melamed A, Sorvillo FJ: The burden of sepsis-associated mortality in the United States from 1999 to 2005: an analysis of multiple-cause-of-death data. Crit Care 2009, 13:R28.

7. van Gestel A, Bakker J, Veraart CPWM, van Hout BA: Prevalence and incidence of severe sepsis in Dutch intensive care units. Crit Care 2004, 8:R153-R162.

8. Flaatten H: Epidemiology of sepsis in Norway in 1999. Crit Care 2004, 8:R180-R184.

9. Linde-Zwirble WT, Angus DC: Severe sepsis epidemiology: sampling, selection, and society. Crit Care 2004, 8:222-226.

10. Silva E, Pedro MA, Sogayar ACB, Mohovic T, Silva CLO, Janiszewski M, Cal RGR, Sousa EF, Abe TP, Andrade J, Matos JD, Rezende E, Assunção M, Avezum A, Rocha PCS, Matos GFJ, Bento AM, Corrêa AD, Vieira PCB, Knobel E: Brazilian Sepsis Epidemiological Study (BASES study). Crit Care 2004, 8:R251-R260.

11. Cheng B, Xie G, Yao S, Wu X, Guo Q, Gu M, Fang Q, Xu Q, Wang D, Jin Y, Yuan S, Wang J, Du Z, Sun Y, Fang X: Epidemiology of severe sepsis in critically ill surgical patients in ten university hospitals in China. Crit Care Med 2007, 35:2538-2546

12. Shen HN, Lu CL, Yang HH: Epidemiologic trend of severe sepsis in Taiwan from 1997 through 2006. Chest 2010, 138:298-304.

13. Záhorec R, Firment J, Straková J, Mikula J, Malík P, Novák I, Zeman J, Chlebo P: Epidemiology of severe sepsis in intensive care units in the Slovak Republic. Infection 2005, 33:122-128.

14. Khwannimit $B$, Bhurayanontachai $R$ : The epidemiology of, and risk factors for, mortality from severe sepsis and septic shock in a tertiary-care university hospital setting. Epidemiol Infect 2009, 137:1333-1341.

15. Rodríguez F, Barrera L, De La Rosa G, Dennis R, Dueñas C, Granados M, Londoño D, Molina F, Ortiz G, Jaimes F: The epidemiology of sepsis in Colombia: a prospective multicenter cohort study in ten university hospitals. Crit Care Med 2011, 39:1675-1682.

16. Jawad I, Luksic I, Rafnsson SB: Assessing available information on the burden of sepsis: global estimates of incidence, prevalence and mortality. J Glob Health 2012, 2:10404

17. Brazilian Institute of Geography and Statistics database. [http://www.ibge. gov.br]. Accessed November 1, 2013.

18. Watson RS, Carcillo JA, Linde-Zwirble WT, Clermont G, Lindicker J, Angus D: The epidemiology of severe sepsis in children in the United States. Am J Respir Crit Care Med 2003, 167:695-701.

19. Dellinger RP, Levy MM, Rhodes A, Annane D, Gerlach H, Opal SM, Sevransky JE, Sprung CL, Douglas IS, Jaeschke R, Osborn TM, Nunnally ME, Townsend SR, Reinhart K, Kleinpell RM, Angus DC, Deutschman CS, Machado FR, Rubenfeld GD, Webb SA, Beale RJ, Vincent JL, Moreno R, Surviving Sepsis Campaign Guidelines Committee including the Pediatric Subgroup: Surviving Sepsis Campaign: International guidelines for management of severe sepsis and septic shock: 2012. Crit Care Med 2013, 41:580-637.

20. Levy MM, Dellinger RP, Townsend SR, Linde-Zwirble WT, Marshall JC, Bion J, Schorr C, Artigas A, Ramsay G, Beale R, Parker MM, Gerlach H, Reinhart K, Silva E, Harvey M, Regan S, Angus DC, Surviving Sepsis Campaign: The Surviving Sepsis Campaign: Results of an international guideline based performance improvement program targeting severe sepsis. Crit Care Med 2010, 38:367-374.

21. Noritomi DT, Ranzani OT, Monteiro MB, Ferreira EM, Santos SR, Leibel F, Machado FR: Implementation of a multifaceted sepsis education program in an emerging country setting: clinical outcomes and cost-effectiveness in a long-term follow-up study. Intensive Care Med 2014, 40:182-191.

22. Sales JAL Jr, David CM, Hatum R, Souza PCSP, Japiassú A, Pinheiro CTS, Friedman G, Silva OB, Dias MD, Koterba E, Dias FS, Piras C, Grupo de Estudo de Sepse do Fundo AMIB, Luiz RR: An epidemiological study of sepsis in intensive care units. Sepsis Brazil Study Rev Bras Ter Intensiva 2006, 18:9-17.

23. Sogayar AMC, Machado FR, Rea-Neto A, Dornas A, Grion CMC, Lobo SMA, Tura BR, Silva CLO, Cal RGR, Beer I, Michels V Jr, Safi J Jr, Kayath M, Silva E: A multicentre, prospective study to evaluate costs of septic patients in Brazilian intensive care units. Pharmacoeconomics 2008, 26:425-434.

24. Rezende E, Silva JM Jr, Isola AM, Campos EV, Amendola CP, Almeida SL: Epidemiology of severe sepsis in the emergency department and difficulties in the initial assistance. Clinics 2008, 63:457-464.

25. Beale R, Reinhart K, Brunkhorst FM, Dobb G, Levy M, Martin G, Martin C, Ramsey G, Silva E, Vallet B, Vincent JL, Janes JM, Sarwat S, Williams MD, PROGRESS Advisory Board: Promoting global research excellence in severe sepsis (PROGRESS): Lessons from an International Sepsis Registry. Infection 2009, 37:222-232.
26. McPherson D, Griffiths C, Williams M, Baker A, Klodawski E, Jacobson B, Donaldson L: Sepsis-associated mortality in England: an analysis of multiple cause of death data from 2001 to 2010. BMJ Open 2013, 3:e002586.

27. Rhee C, Gohil S, Klompas M: Regulatory mandates for sepsis care reasons for caution. N Engl J Med 2014, 370:1673-1676.

28. Govindan S, Shapiro L, Langa KM, Iwashyna TJ: Death certificates underestimate infections as proximal causes of death in the U.S. PLoS One 2014, 9:e97714.

29. Iwashyna TJ, Odden A, Rohde J, Bonham C, Kuhn L, Malani P, Chen L, Flanders S: Identifying patients with severe sepsis using administrative claims: patient-level validation of the Angus Implementation of the International Consensus Conference Definition of Severe Sepsis. Med Care 2014, 52:e39-e43.

30. Liu V, Escobar GJ, Greene JD, Soule J, Whippy A, Angus DC, Iwashyna TJ: Hospital deaths in patients with sepsis from 2 independent cohorts. JAMA 2014, 312:90-92.

doi:10.1186/s13054-014-0608-8

Cite this article as: Taniguchi et al: Sepsis-related deaths in Brazil: an analysis of the national mortality registry from 2002 to 2010. Critical Care 2014 18:608.

\section{Submit your next manuscript to BioMed Central and take full advantage of:}

- Convenient online submission

- Thorough peer review

- No space constraints or color figure charges

- Immediate publication on acceptance

- Inclusion in PubMed, CAS, Scopus and Google Scholar

- Research which is freely available for redistribution

Submit your manuscript at www.biomedcentral.com/submit
C) Biomed Central 